\title{
Franz Kühn
}

Grundriß der Kulturgeographie

von Argentinien 



\title{
Grundriß der Kulturgeographie von Argentinien
}

Untersuchung eines südamerikanischen Lebensraumes nach anthropogeographischen und geopolitischen Gesichtspunkten

\author{
von \\ Dr. Franz Kühn \\ ehem. argentinischen Univ.-Prof.
}

Mit $38 \mathrm{Abb}$. und 25 Karten und Plänen

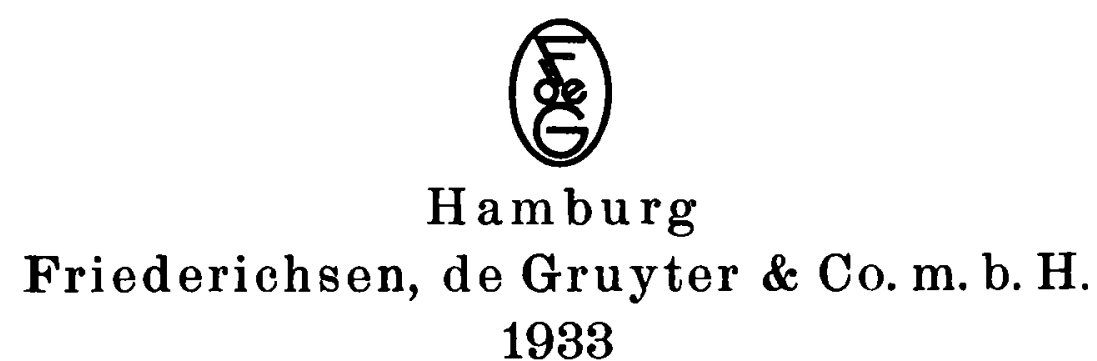


Alle Rechte vorbehalten

Copyright 1933 by Friederichsen, de Grayter \& Co.

Reservados los derechos de

reproducción y traducción. 


\section{ERNESTO QUESADA,}

\section{dem großen Argentiner,}

dem Soziologen und Amerikanisten,

dem Freunde Deutschlands

im 75. Jahre seines reich gesegneten Lebens

verehrungsvoll gewidmet 
